\title{
El auto sacramental \\ y la alegorización de la historia: \\ El socorro de Cádiz \\ de Juan Pérez de Montalbán
}

\author{
Teresa Ferrer Valls \\ Universitat de València \\ m.teresa.ferrer@uv.es
}

Fecha de recepción: 03/09/2012, Fecha de publicación: 21/12/2012

\section{Resumen}

Este trabajo estudia la relación excepcional entre acontecimientos históricos y género sacramental, a partir de un auto que se dio por perdido durante bastantes años. Se trata de El socorro de Cádiz de Juan Pérez de Montalbán en el que se alegoriza la defensa de Cádiz contra los ingleses en 1625.

Palabras clave

Juan Pérez de Montalbán; auto sacramental; defensa de Cádiz; historia dramatizada

\begin{abstract}
Sacramental play and the alegorization of history: Juan Pérez de Montalbán's El socorro de Cádiz

This paper analyzes the exceptional relationship between historical events and the sacramental genre, based on an «auto» that was considered lost during many years. This «auto» is El socorro de Cádiz by Juan Pérez de Montalbán, in which the playwright allegorizes the defense of Cádiz against the English in 1625.
\end{abstract}

\section{Keywords}

Juan Pérez de Montalbán; sacramental play; defense of Cádiz; theatricalized history 
En 1976, cuando M. G. Profeti publicaba su bibliografía sobre Juan Pérez de Montalbán, el manuscrito del auto El socorro de Cádiz se encontraba en paradero desconocido. La investigadora tuvo que recurrir entonces a la descripción realizada en su día, en 1922, por Alenda y Mira, quien pudo consultarlo y dio cuenta de él en su catálogo de autos, en el que afirmaba que el manuscrito era una copia del xvir y pertenecía en ese momento al bibliógrafo Sancho Rayón. ${ }^{1}$ Todavía recientemente Cruickshanck (2011: 147) lo daba por perdido, aunque se incluye en el más reciente catálogo de obras dramáticas, el de Urzáiz (2002: II, 514). Actualmente el manuscrito se encuentra en los fondos de la Biblioteca Lázaro Galdiano (signatura MC 6-10) y resulta ser el único testimonio conocido de la obra (figura 1). Aunque Profeti, sin haber visto el manuscrito, conjeturase que podía tratarse de un autógrafo (1976: 386), y como tal lo cataloga Urzáiz (2002: II, 514), lo cierto es que la consulta directa del mismo, desde mi punto de vista, corrobora el juicio de Alenda de que se trata de una copia, pues quien la hizo incurrió en errores mecánicos que no pueden ser del autor. En el catálogo de manuscritos de esta biblioteca se describe de hecho como una "copia con caligrafía cuidada y buena presentación" (Yeves, 1998: I, 800-801). ${ }^{2}$ La pieza fue desgajada de un volumen que debía contener otras obras, pues su numeración comienza en el folio 263 r. y finaliza en el 286v.

Ya el mismo Alenda, en su catálogo, se refería a este auto como una composición de circunstancias. Ciertamente El socorro de Cádiz pertenece a ese grupo reducido de autos que, a pesar de tener como objetivo la exaltación de la eucaristía, conectan con una circunstancia histórica contemporánea, a la que se da un tratamiento alegórico. Enrique Rull se ha referido a este tipo de autos que podríamos considerar doblemente de circunstancias, pues se vinculan a la conmemoración puntual de una ocasión festiva, como lo era el Corpus, pero además enlazan con un acontecimiento que para el público tenía el interés de la contemporaneidad. En un reciente trabajo (en prensa), el citado investigador analiza algunos de estos autos en relación con los acontecimientos vinculados a la corte y a la familia real, como es el caso, por ejemplo, de La jura del Príncipe, de Antonio Mira de Amescua, de 1632; o el auto de Calderón El nuevo palacio del Retiro, de 1634, que conmemoraba la reciente construcción y mejoras introducidas en este espacio de recreo para la familia real; o el titulado El consumo del vellón, atribuido con ciertas dudas a Calderón, y compuesto

1. Véase Profeti (1976: xvII, n. 18 y 386) y Alenda y Mira (1922: 493-495). Mi trabajo se beneficia de mi vinculación a los proyectos de investigación financiados por el MINECO y fondos FEDER FFI2011-23549 y CDS2009-00033.

2. Esta copia no se encuentra catalogada y estu- diada todavía en la base de datos Manos teatrales, proyecto en curso dirigido por Margaret R. Greer, que permite la identificación de autores y copistas http://manosteatrales.org [consulta 27/08/2012]. $\mathrm{Su}$ análisis podría esclarecer definitivamente esta cuestión. 


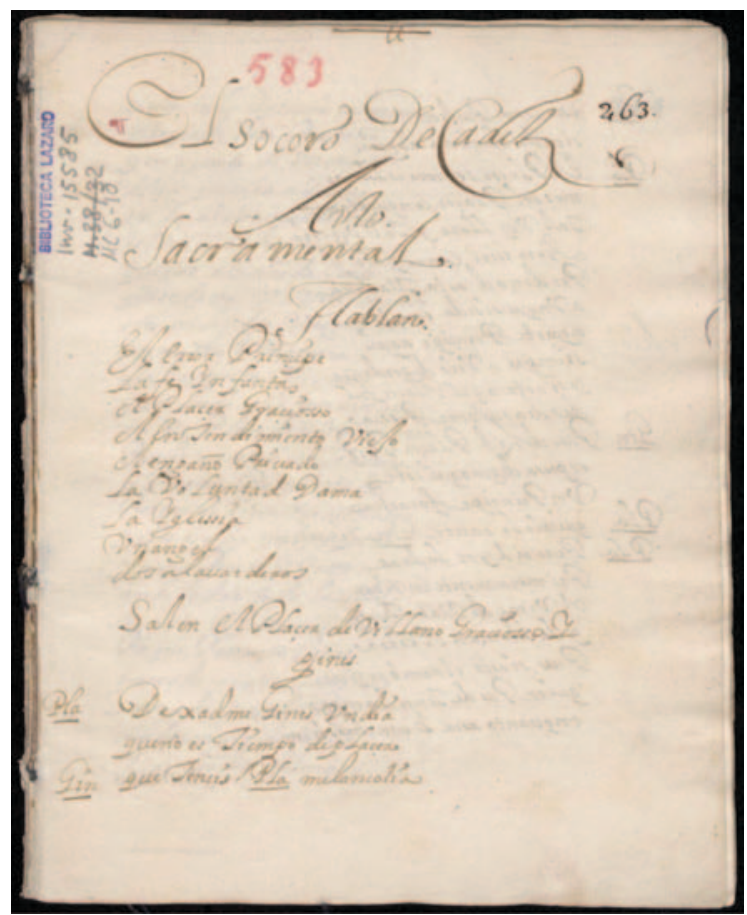

Figura 1.

Juan Pérez de Montalbán, El socorro de Cádiz. Madrid. Biblioteca Lázaro Galdiano.

probablemente en 1660, en el que se vincula el mensaje religioso eucarístico con una circunstancia concreta, la acuñación de una nueva moneda de vellón. ${ }^{3}$

Si llevaba razón Menéndez Pelayo, el primero en poner su pluma a la tarea de escribir este tipo de autos de circunstancias fue Lope de Vega. En su estudio preliminar a la edición académica de los autos y coloquios del dramaturgo, el investigador escribía, refiriéndose al auto Las bodas del Alma y el Amor divino, incluido en El peregrino en su patria (1604): «la curiosidad de este auto [...] nace de ser el más antiguo que conocemos de los llamados de circunstancias». Efectivamente en este auto Lope alegorizó las bodas entre Felipe III y Margarita de Austria que tuvieron lugar en Valencia, y a cuyos festejos asistió el dramaturgo como secretario del marqués de Sarria, después conde de Lemos, don Pedro Fernández de Castro. Se supone, a partir de las mismas alusiones de Lope en

3. Sobre este auto puede verse Valladares Ramírez (1999: 129-140). 
El peregrino, que el auto se representó en Valencia, en las fiestas del Corpus de 1599, poco después de las bodas reales. Es por este hecho uno de los autos más conocidos del Fénix. No obstante, es bien sabido que la vinculación entre circunstancia histórica y auto sacramental resulta algo extraño en la concepción de este género dramático, y de ello es testimonio el mismo juicio emitido en su día por Menéndez Pelayo sobre los autos de circunstancias, a los que consideraba un "género híbrido y monstruoso, en que con torpe amalgama, que solo para espectadores de tan robusta fe pudo dejar de ser irreverencia y escándalo, se confundía lo sagrado con lo profano en una misma acción alegórica» (1949: 37).

Hay autos en que podemos encontrar alusiones puntuales a hechos o elementos de la realidad contemporánea. Así, en algunos versos Del pan y el palo de Lope de Vega se alude al casamiento del Sol y la Luna, es decir, el príncipe Felipe IV y la reina Isabel de Borbón. En otros, como El valle de la Zarzuela de Calderón, se encuentran referencias a la realidad, al alegorizarse el espacio de los campos del palacio de recreo de la familia real, empleando la fama alcanzada por Felipe IV como cazador y aludiendo quizá al conocido episodio que protagonizó al matar un toro de un arcabuzazo. ${ }^{4}$ Pero los autos sacramentales en que se alegoriza en clave espiritual un acontecimiento histórico contemporáneo no son muchos, lo que explica la consideración de Menéndez Pelayo de esos autos como un género hibrido, entre el drama histórico y el auto sacramental. ${ }^{5} \mathrm{El}$ auto de Montalbán que me ocupa pertenece a este pequeño grupo en el que no encontramos una mera alusión a un hecho real, sino que el auto mismo se convierte en dramatización de todo un hecho histórico contemporáneo en clave alegórica, el ataque a Cádiz en noviembre de 1625, propiciado por el rey Carlos I de Inglaterra y su valido el Duque de Buckingham. La flota inglesa, aliada con los holandeses, arribó a Cádiz el 1 de noviembre. La rápida reacción de su gobernador, don Fernando Girón, y el socorro inmediato del Duque de Medina Sidonia, ocasionaron el fracaso de los ingleses, que pretendían interceptar la llegada de los galeones españoles cargados con la plata procedente de América. Perdieron un elevado número de naves y hombres, y zarparon de la bahía de Cádiz el 7 de noviembre.

El impacto inmediato que tuvo esta victoria dio lugar a varias relaciones que recogían, en tono de exaltación patriótica, el suceso, como la de Gamboa y Eraso, o la anónima en que se incluye una carta del gobernador Fernando Girón al duque de Medina Sidonia, Juan Manuel Pérez de Guzmán, publicadas en el mismo año de 1625 . Sobre este acontecimiento Zurbarán realizaría pocos años después su cuadro La defensa de Cádiz como encargo para decorar el Salón de Reinos del Palacio del Buen Retiro, el mismo lugar para el que Velázquez ejecu-

4. Sobre este acontecimiento reflejado en El valle de la Zarzuela, véase Greer (1997). 5. En algunos trabajos recientes sobre los autos de Calderón se señala la vinculación con hechos históricos de algunos de ellos: véanse, por ejemplo, Garrot Zambrana (2002), Rull (2004: 133-201) y ahora Sáez (2012). 
tó su famoso cuadro sobre La rendición de Bredá, también conocido como Las lanzas (figura 2).

En la pintura de Zurbarán, hoy en el Museo del Prado, se representa a don Fernando Girón, gobernador de la plaza, dando órdenes a sus capitanes, sentado en una silla (figura 3). La relación de Jerónimo de la Concepción destaca el protagonismo que en el rechazo de la flota enemiga tuvo Fernando Girón, y lo evoca en esa misma disposición que el cuadro recoge: «No se descuidaba a esta sazón don Fernando Girón, que aunque oprimido de la vejez y otras enfermedades [el gobernador padecía gota], como otro Antonio de Leiva en el cerco de Pavía, desde una silla, donde se hizo llevar, disponía las órdenes» (1690: 460).

Como en el caso de la rendición de Bredá, que tuvo su reflejo en el teatro por medio de la obra El sitio de Bredá de Calderón, la defensa de la plaza gaditana dio lugar al menos a dos obras que entroncaban directamente con este acontecimiento: una de ellas la comedia de Rodrigo de Herrera titulada La fe no ha menester armas y venida del inglés a Cádiz; la otra el auto de Montalbán El socorro de Cádiz.

La versión novelesca de esta invasión es la que recogen ambas obras: el despecho de Carlos, al haber sido rechazado por la infanta María como marido, habría desencadenado el ataque inglés. Hay que recordar que dos años antes, en 1623, Carlos, entonces todavía príncipe de Gales — título que ostentó como heredero, antes de subir al trono- había llegado a Madrid, acompañado del marqués — después duque - de Buckingham, para tratar de cerrar el acuerdo matrimonial entre ambas coronas. La visita desencadenó un sinfín de entretenimientos para agasajar al príncipe, al que se alojó en el Alcázar de Madrid. Su estancia se prolongó durante seis meses, entre el 17 de marzo y el 9 de septiembre de 1623. Hubo numerosos espectáculos de todo tipo: se representaron comedias, se organizaron juegos de cañas, toros, cacerías, banquetes y otras diversiones. Hay un conocido grabado que reproduce el momento de la entrada oficial del príncipe en Madrid, bajo palio. A la izquierda del grabado puede verse un tablado con varios actores representando (figura 4). ${ }^{6}$

Juan Ruiz de Alarcón recibió el encargo del Duque de Cea de escribir una relación en verso celebrando la venida del príncipe inglés a la corte española,

6. La documentación de la época atestigua un acuerdo, fechado en Madrid el día 23 de marzo, entre el Ayuntamiento de esta ciudad y los autores de comedias Juan de Morales, Cristóbal de Avendaño, Manuel Vallejo y Juan Bautista Valenciano para que representaran el domingo 26 de marzo con sus compañías en varios tablados levantados en las calles con motivo de los festejos preparados para el recibi- miento del heredero inglés. Asimismo se sabe que en dichas celebraciones también tomó parte el autor de comedias Pedro de Valdés, ya que así se indica en la relación de los gastos que hizo el Ayuntamiento de Madrid con motivo de dichos fastos. Sobre estos directores de compañías, y sobre esta documentación véanse las entradas correspondientes de DICAT, en Ferrer Valls et al. (2008). 


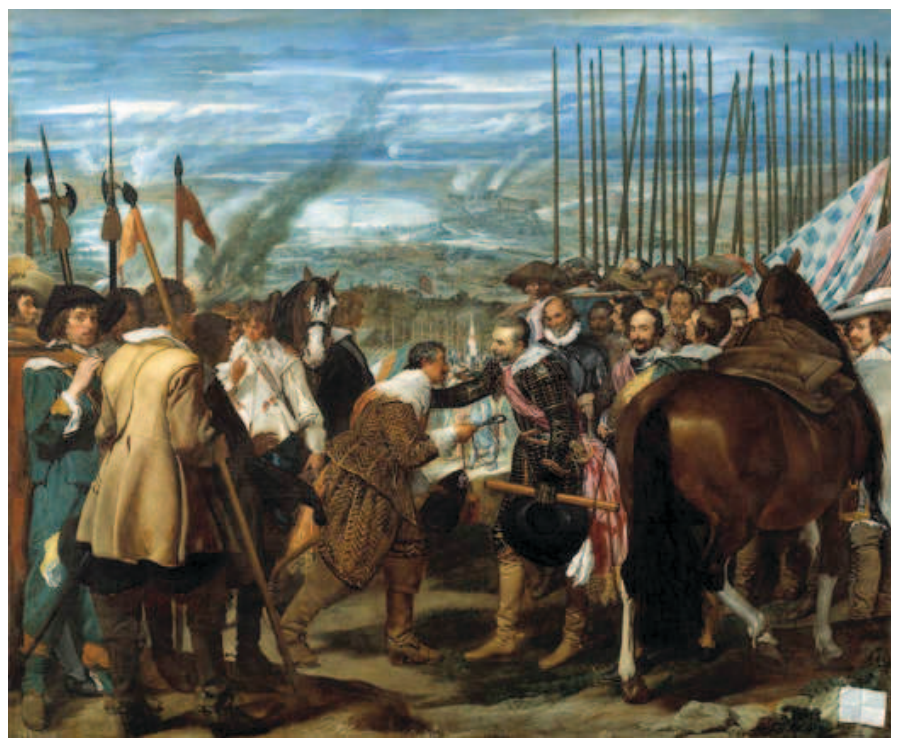

Figura 2.

Diego Rodríguez de Silva y Velázquez, Las lanzas, o La rendición de Bredá (1635). Madrid. Museo Nacional del Prado..

para el que contó con la colaboración de Mira de Amescua y otros autores, un poema que desencadenó una sonora burla, en forma de décimas satíricas, compuestas, entre otros, por Góngora, Quevedo, Lope de Vega, Montalbán o el mismo Mira de Amescua, quien reclamaba por su participación la mitad del dinero que Alarcón había recibido de manos de Cea. ${ }^{7}$

El acuerdo matrimonial entre las dos coronas no llegó a buen puerto. La versión que debió de circular popularmente presentaba al príncipe Carlos como un galán enamorado, despechado por el rechazo de la infanta española, para la cual resultaba insalvable el obstáculo de la diferente fe del futuro esposo. Es cierto que entre los muchos escollos para la llegada a buen puerto del concierto matrimonial no fue detalle menor la diferencia religiosa entre los contrayentes. De hecho hubo que pedir dispensa papal a Gregorio XV, que fue favorable al matrimonio, aunque instando en carta personal a Felipe IV a la defensa del catolicismo en Inglaterra. La muerte del papa y el ascenso de Urbano VIII, en julio de 1623, que exigía la obtención de una nueva dispensa papal, provocó

7. Sobre la visita del príncipe de Gales, puede verse Puyuelo y Salinas (1962). Sobre las implicaciones literarias y festivas de esta visita, con es- pecial mención al poema encargado a Alarcón y a las reacciones que este produjo entre los poetas de la Academia de Madrid, véase Redondo (1998). 


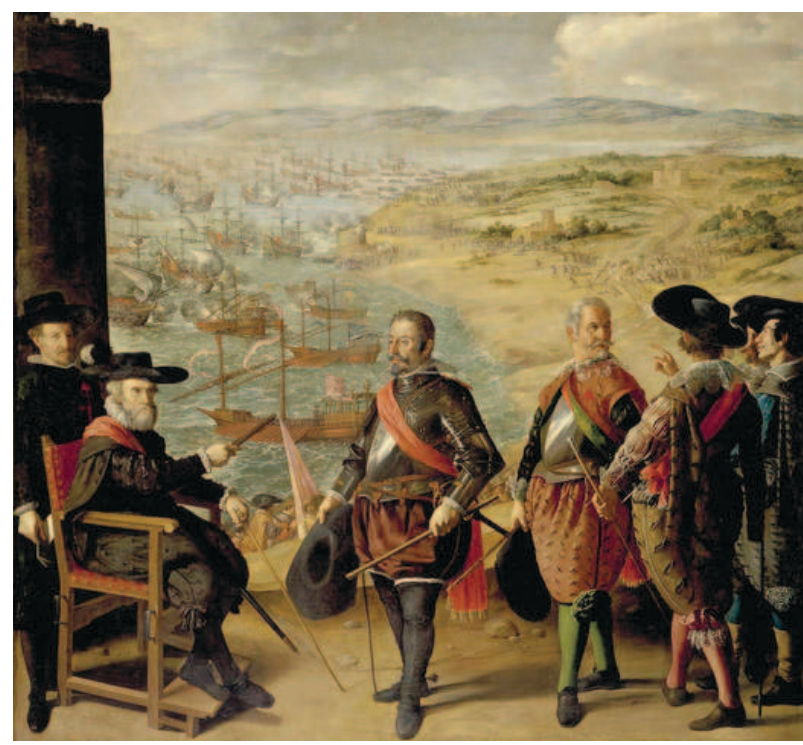

Figura 3.

Francisco de Zurbarán, La defensa de Cádiz contra los ingleses (1634). Madrid. Museo Nacional del Prado.

una nueva dilación en el proceso y parece que influyó en el regreso a su país del príncipe, sin que se hubiese cerrado en firme la alianza. Felipe IV también nombró una junta de teólogos para aconsejarle sobre las cláusulas que, en materia de religión, debían incluirse en el acuerdo. De manera que la cuestión religiosa no fue un escollo menor, pero hay que señalar que no fue el único, y hubo otras importantes cuestiones de índole política que influyeron en la ruptura de las relaciones al regreso de Carlos a Inglaterra. ${ }^{8} \mathrm{El}$ auto sacramental de Montalbán, al igual que la obra de Herrera, insisten, no obstante, en el aspecto religioso como único obstáculo, y en una interpretación romántica del ataque a Cádiz, motivado por el despecho del supuestamente enamorado príncipe inglés. Es la versión simplificada de lo acontecido, que debió dejar honda impresión en las capas más amplias de la población, alimentada por rumores sobre el ímpetu del príncipe, que de hecho se había presentado de improviso en España, tras un largo trayecto de incógnito, según se decía, apasionado de amor por la infanta. Es cierto que

8. Para un análisis de los diferentes problemas que, por parte inglesa y española, planteaba la alianza matrimonial entre las dos Coronas, véase Sanz Camañes (2002). Para el papel del
Conde-Duque de Olivares en estas negociaciones y después en el consiguiente ataque de los ingleses a Cádiz, véase Elliott (1991: 213-223 y 246-50). 


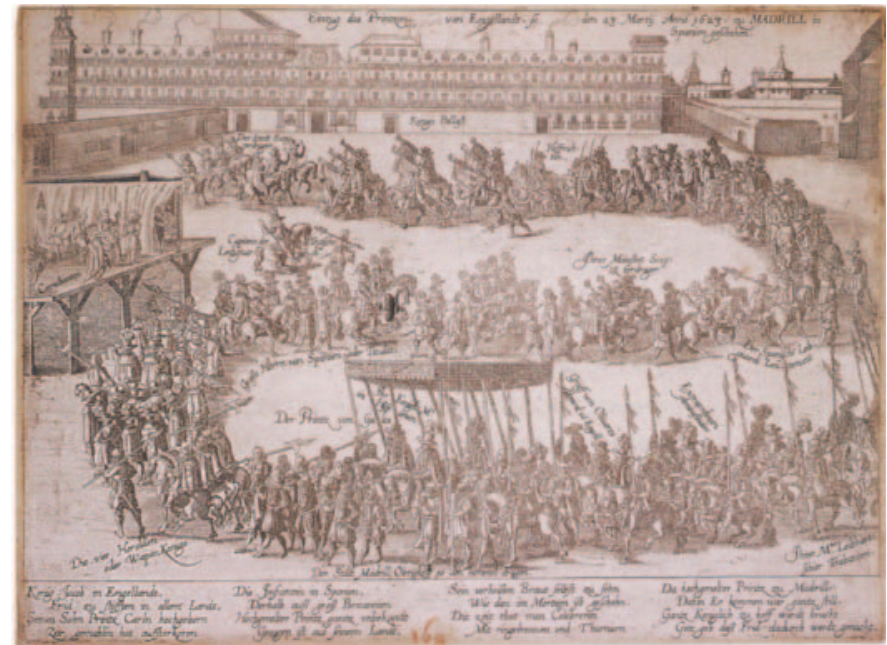

Figura 4.

Llegada al Alcázar de Madrid del Príncipe de Gales. Madrid. Museo de Historia.

algunas relaciones de fiestas se hacen eco del arrobamiento del príncipe inglés, que en los actos públicos, según se contaba también, se mostraba embobado mirando a la infanta. Pero hay que tener en cuenta que estos detalles son tópicos, y a veces exageraciones, de las relaciones de esta naturaleza cuando mediaban compromisos o conciertos matrimoniales.

El anónimo autor de las Noticias de Madrid da cuenta de un episodio que se reproduce en el auto de Montalbán, y que debió de correr por la corte como la pólvora, contribuyendo a afianzar la idea de que la infanta había provocado un gran impacto en el corazón del príncipe extranjero:

A 27 [...], este día andando por la mañana la señora infanta dońa María paseando por el parque tomando el acero, que andaba opilada, quiso pasar a verla el Príncipe por los jardines de su cuarto y, habiendo hallado la puerta cerrada, pidió a los guardias que le abrieran las puertas y, no le obedeciendo, saltó por encima de las paredes. Anduvieron los guardadamas y mayordomos a detenerle suplicando a $\mathrm{Su}$ Alteza se volviese a salir. Hubo algunas réplicas, a que se dejó convencer diciendo que un viejo había podido más que un mozo. La señora infanta no volvió la cabeza ni se dio por enterada. ${ }^{9}$

Sobre este doble entramado (la preocupación por la defensa de la fe que mueve a Felipe IV y a su hermana, y el enamoramiento del príncipe de Gales 
de la infanta) se teje tanto la comedia de Herrera, como el auto de Montalbán. La obra de Herrera resulta una curiosa obra de circunstancias, en la que, sin máscaras interpuestas, el espectador asiste a la intervención de personajes contemporáneos como el Conde-Duque de Olivares, caracterizado en el elenco como «barba», el mismo Felipe IV y la reina Isabel de Borbón, la infanta María, el famoso coleccionista Conde de Gondomar, que había sido embajador de España en Inglaterra y tuvo, por ello, su cuota de protagonismo durante la estancia del de Gales, y el mismo príncipe, caracterizado justamente como "galán» en el elenco, y su acompañante, el Marqués de Buckingham. Al igual que ocurre en el auto de Montalbán, la primera jornada de la comedia se dedica a dramatizar las circunstancias que justificarán el posterior asalto a Cádiz, desde la interpretación que debió ser la más divulgada. La obra de Herrera se abre con la llegada de improviso del príncipe enamorado, que declara a Gondomar:
el puerto de mi esperanza
el norte de mis deseos
es la Infanta, en cuyos ojos
morir y abrasarme siento $[\ldots]$
Tratad con el Conde-Duque
todos de mi casamiento,
atropellad imposibles,
y si no dadme por muerto.

La explicación que justificaría el rechazo por parte de la Corona, fundado en motivos religiosos, se expone desde el comienzo por boca de Felipe IV ante Olivares:

El Príncipe, Conde, viene a casarse con mi hermana, y en una infanta cristiana un hereje no conviene.

No por materia de Estado anteponer es razón contra nuestra religión el cortesano cuidado.

Del mismo modo, en boca del Príncipe, el despecho al ser rechazado justifica la amenaza de invasión: "pero si vuelvo sin ella [...]/ que ha de verse ardiendo España, / y ha de hacer en ella robos / la furia de mis armadas».10

La comedia de Herrera, como apuntó Cruishanck (1993:15), se debió de escribir entre noviembre de 1625, tras la retirada de los ingleses de Cádiz, y

10. Dejo para otro lugar el análisis detallado de esta comedia. Las citas anteriores en Herrera (1762: 2-3, 3 9). Cuando cito de textos antiguos, aplico criterios ortográficos, puntúo y acentúo según normas modernas a lo largo del trabajo. 
antes de marzo de 1626, cuando se celebraron las cortes de Monzón, a las que en la obra se alude como un suceso futuro. Por tanto, se compuso en fechas muy cercanas al auto sacramental de Montalbán El socorro de Cádiz que, según creo, debió de estrenarse en Sevilla, en el Corpus de 1626, poco después de su composición y del suceso bélico al que alude. A esto apuntan la fecha y lugar que figuran al final del manuscrito: «Sevilla, y 6 de abril de 1626 [...] El licenciado Juan Pérez de Montalbán» (286v.). Este colofón indica que la copia se realizó probablemente a partir del original autógrafo o de una copia de este. A la representación sevillana apunta asimismo la relevancia que adquiere en el auto la Ciudad de Sevilla, a la que se menciona en varios momentos, pero en especial en el apoteósico final que cierra la obra, con la aparición en escena de una galera con los patronos de la ciudad y el personaje de la Iglesia, portando en ella el pan y el vino que han de servir para el socorro de la ciudad, en clara alusión a la eucaristía.

El ataque a Cádiz tuvo un gran eco en tierras andaluzas y las relaciones de la época que lo describen insisten en la celeridad con que algunos nobles, órdenes religiosas y autoridades municipales y eclesiásticas se aprestaron a enviar socorro en forma de víveres, animales y hombres, ocupando un lugar relevante la Ciudad de Sevilla. No resulta sorprendente que, en este contexto, el del Corpus, una fiesta de gestión municipal, se acogiese con gusto un auto que retomaba un tema de tremenda actualidad, destacando, en el momento culminante de la representación, el papel jugado por la Ciudad y por su Iglesia en el suministro de víveres y ayuda.

El Corpus de 1626 fue el 11 de junio. La documentación exhumada de los archivos municipales sevillanos no menciona el título de los autos representados en esta ocasión, aunque sí conocemos los nombres de los dos autores de comedias que representaron en este año en esta festividad, que fueron José de Salazar y Roque de Figueroa. Este último recibió la joya o premio a la compañía que mejor había representado. ${ }^{11}$

Parece que el auto tuvo difusión en América. Lohman, en su estudio sobre el teatro en Lima, da cuenta de la representación, ocho días después del Corpus de 1629, en la Octava del Corpus, de un auto titulado El cerco de Cádiz, que probablemente fuera el de Montalbán. ${ }^{12}$ El Corpus de 1629 se celebró el 14 de junio, y el auto de Montalbán se representaría, según esto, el 22 de este mismo mes en Lima.

Como Herrera en su comedia, Montalbán dedica la primera parte del auto a establecer los antecedentes que justifican la invasión inglesa, en la que se centra la segunda parte de la obra. La trama funciona en muchos momentos a la manera de una comedia, pues el Príncipe si por un lado se presenta como alegoría

11. Para todos estos datos, véanse las entraCAT, Ferrer Valls et. al. (2008). das de ambos autores en la base de datos DI-

12. Lohmann (1945: 203). 
del Error, por otro es un ser humano enamorado de la Infanta, que se expresa a la manera de un galán de comedia:

\author{
¡Ay de mí, \\ esta mujer me mató! \\ ¿No ha visto un rayo bajar \\ sobre una ilustre encina \\ y con licencia divina \\ romper herir y abrasar \\ cuanto encuentra sin dejar, \\ hidrópico de sus llamas, \\ hojas, troncos y retamas \\ hasta que su furia fiera \\ construye pálida hoguera \\ a los huesos de las ramas? \\ Pues a mí sus ojos bellos, \\ rayos que del cielo bajan \\ de suerte mi ser ultrajan \\ que me desconozco en ellos. \\ Aquellos rubios cabellos, \\ aquella madeja rica, \\ que amorosamente hechiza, \\ no es oro, no, fuego sí; \\ yo le toqué, yo le vi; \\ humo soy, ya soy ceniza (265r.-265v.).
}

Asistimos a la teatralización incluso de aquella anécdota, recogida en alguna crónica de la época, según la cual el príncipe habría intentando hablar en privado a la infanta ocasionando un escándalo al saltar el muro de los jardines de palacio. En el auto este episodio se sitúa después del momento en que el Príncipe recibe una carta de la Infanta rechazando su matrimonio e instándole a que parta de la corte. El Príncipe desea hablar con ella, pero la Infanta se ha encerrado en su cuarto. El Príncipe insiste: «he de verla y hablarla, / que verla, si me voy, no es agraviarla; / y así ningún intente / ponérseme delante locamente / porque entre aquestos brazos / le haré, jviven los cielos!, más pedazos / que tengo yo de penas, / el cielo luces y Neptuno arenas» (270r.).

Voluntad, la dama de la reina, trata de impedir el atropello. El Príncipe entonces da voces, gritando a la Infanta que le abra la puerta. Es en ese momento cuando se produce un buscado efecto escénico, apoyado por la música, que la acotación detalla:

Toquen chirimías y, tirándose un lienzo hacia arriba, descúbrase un oratorio muy curioso, que coja todo el espacio de la pared por lo alto, y un estrado con sus almohadas, donde estará la Infanta rezando en unas Horas, y el Placer y la Voluntad se pongan a rezar con ella (271r.).

La sola visión de la Infanta templa la cólera del Príncipe. Con frialdad, al igual que una dama de comedia, recriminará al inglés: «¡Y es cortesía / para ver- 
me ofenderme?/ ¿Eso llamáis amor? ¿Eso es quererme?» (271r.). Para enseguida recordarle, sin embargo, lo que ella representa en el plano simbólico: «Yo soy la Fe divina, / la que sin ojos ve la esencia trina. / Idos a vuestra tierra, / que estará mal sin vos Ingalaterra, / y no es razón que quede / el Error en España, porque puede / serla de daño» (271v.).

En el auto la Infanta se convierte así en alegoría de la Fe, una transformación que casaba muy bien con la creencia generalizada de su aversión al matrimonio con el de Gales por motivos de religión. Entre ambos personajes se suceden varios diálogos de debate religioso, en los que se presenta siempre a la Fe/la Infanta victoriosa, debates que sirven para que esta ponga a prueba al Príncipe ante los ojos de los espectadores. Por medio de los apartes del Príncipe se revelan sus malas intenciones, como cuando reconoce su hipocresía al haber simulado que los argumentos religiosos de la Infanta lo han convencido de su error: «Por lograr mi pretensión, / quiero seguir su opinión» (267r.). Por otro lado, los apartes de la Infanta sirven para desvelar ante el espectador su desconfianza hacia el inglés: «Pero ya está tu intención/ bien conocida, ay de mí / [...] ya te entiendo, ah fementido, / soy en efeto mujer» (267r).

El auto se hace eco también de otro elemento de la realidad acontecida, ya que si Felipe IV reunió una junta de teólogos para tratar sobre la conveniencia del matrimonio y sus condiciones, en el auto de Montalbán la Fe decide reunir a su Consejo para hacer lo propio: «que en mi Consejo / se mire como en espejo / lo que convenga a los dos» (267v.).

El núcleo central del debate gira en torno al tema de la eucaristía. Escuchamos así al Príncipe cuestionar este misterio en versos como estos: "Que el Hijo de Dios sea hombre / y engendrado de su idea, / vaya. Pero, ique se crea / en fe solo de la fe, / que en cuerpo y alma esté / en los cercos de una oblea!» (266v.). Los argumentos religiosos se entremezclan con las consideraciones de carácter humano, en ese maridaje híbrido que tanto desagradaba a Menéndez Pelayo. Así, la Infanta rechaza como marido al Príncipe ( «No sois vos para marido!») con el argumento de que una vez gozada, al mes de casada se aburrirá de ella, como suele suceder con aquel esposo que:

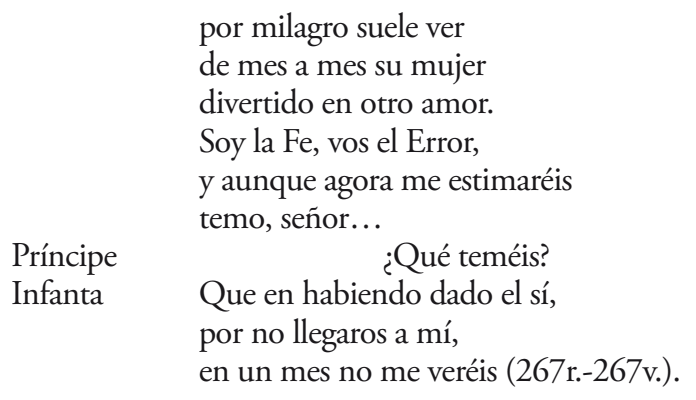

Cuando el Príncipe, cual galán de comedia, solicita tocar su mano, la Infanta 
reaccionará como una dama ofendida en su honra: «¿Qué hacéis, / necio, atrevido, villano?» (267v.).

El personaje cómico, representado por Placer, llegará a aconsejar al Príncipe, tras este chasco amoroso, en tono grosero, que acuda al Rastro donde "se ahíte de alabastro», pues allí las mujeres «se dan con vientre y todo» (268r.).

Los guińos a circunstancias de la realidad salpican toda la obra, como sucede con la alusión del Príncipe a su entrada bajo palio en Madrid: «Yo pensé que concertar / recibirme en el lugar / con fiesta y palio de plata...». Pero Placer lo interrumpe y desengaña: «Pues no, señor, no se trata, / sino cómo te ha de echar [el Consejo]» (268r.). En boca de Placer encontramos la alusión implícita a la ejecución de María Estuardo como antecedente que justifica los recelos de la Infanta respecto al matrimonio con el Príncipe: «En vuestra tierra no fuera / la primer reina que hubiera / muerto de buena cristiana» (268v.). El Príncipe es acompańado por su privado, el Engaño, trasunto del de Buckingham que le acompañó durante su estancia en Madrid. Por su parte, la voz del Consejo la representa el Entendimiento, en el que pueden verse claras alusiones a don Fernando Girón. La primera acotación, en que se da cuenta de la salida de este a escena, exige: «Toquen cajas y sale el Entendimiento, con barba muy cana, y una encomienda de San Juan y un bastón» (279v.). Don Fernando Girón tenía una edad avanzada, y de hecho se retiró tras la hazaña de la defensa gaditana. Era capitán general de la infantería de Cádiz, y caballero de San Juan de Jerusalén, honores ambos que se traducen en el bastón de mando y la cruz militar exigidos por la acotación. Era miembro del Consejo de Guerra y del Consejo de Estado del rey Felipe IV, circunstancia a la que se refiere también la Infanta en otro lugar: «Llámame tú, Voluntad, / con cuidado y diligencia / a mi Entendimiento, que es / de mi Consejo de Guerra» (279r.).

En otros parlamentos encontramos alusiones a personajes relevantes en el acontecimiento bélico, como es el caso de las referencias, puestas asimismo en boca de la Infanta, no solo a don Fernando Girón, sino también al duque de Medina Sidonia, don Juan Manuel Pérez de Guzmán, a don Lorenzo de Cabrera, castellano de la fortaleza de Cádiz (uno de los personajes que quizá es representado también en el cuadro de Zurbarán), e incluso a un humilde platero, cuya valerosa actuación se destacó en algunas relaciones de la época, como la anónima Copia de la carta que el señor don Fernando Girón [...] con el valeroso hecho que hizo el mancebo Platero, hijo de Sevilla (1625):

Los santos han de inviarme, acaso porque tu niegas su divina invocación, soldados que me defiendan. Domingo dará un Guzmán que de su casa decienda [...] Juan, en aquesta encomienda, un general que os retire; 
y desde su propia hoguera

Lorenzo dará un Lorenzo [...]

Y así Eloy, ${ }^{13}$ por su grandeza,

dará un platero que esmalte,

con sangre propia y ajena,

esa playa (282r.-282v.).

Se trata de versos que encierran referencias divulgadas en las crónicas de los hechos y que para el público contemporáneo debían resultar bastante transparentes, como esta otra de Placer que alude a la embriaguez de los soldados ingleses, entregados al saqueo de las casas abandonadas en las aldeas cercanas a Cádiz: «traiga pan / y vino, que en las aldeas / no se halla; y todo el vino / aquella canalla fiera / se lo bebió el otro día» (284r.). ${ }^{14}$

$\mathrm{Al}$ ser El socorro de Cádiz un auto tan claramente alusivo a una circunstancia histórica, la ubicación espacial está determinada, a diferencia de la indeterminación que caracteriza en general al auto sacramental. La acción se traslada desde el palacio real, en Madrid, en donde transcurre la primera parte, hasta las murallas de Cádiz, en donde se desarrolla argumentalmente la segunda parte. Este cambio va acompañado de una transformación visual, escenográfica y de vestuario. Si en la primera parte del auto la Infanta, como indica la acotación, «sale con un vestido entero, llevando la Voluntad la falda» (264v.), en la segunda parte una acotación exige:

Parezca la Infanta en lo alto de la muralla de Cádiz con vaquero, espada y sombrero de plumas, y una cruz en lugar de bastón. A un lado la Voluntad, también con espada, y a otro el Placer, armado graciosamente de guadameci; y en lo alto el estandarte de la Fe, que en la Inquisición le darán (275v.).

La puesta en escena buscó un efectivo impacto visual, que se pone de relieve en las elaboradas acotaciones que se integran en el auto. Así, la escena que representa el palacio real, quizá con una pintura de fondo, se descompone parcialmente al abrirse un lienzo que deja ver un oratorio con la infanta en lo alto del teatro, como se puede ver en la acotación, ya citada anteriormente:

Toquen chirimías y, tirándose un lienzo hacia arriba, descúbrase un oratorio muy curioso, que coja todo el espacio de la pared por lo alto, y un estrado con sus almohadas, donde estará la Infanta rezando en unas Horas, y el Placer y la Voluntad se pongan a rezar con ella (271r.).

13. San Eloy es el patrón de los plateros.

14. Así se hace eco Jerónimo de la Concepción al hablar de los soldados enemigos que perpetraron el «pillaje y robo de algunas caserías» y la destrucción de una ermita y «an- daban estos sin orden cebados en el saco, y embriagados con el mucho y buen vino, dieron ocasión a que el Duque, que guardaba la Puente, [...] les matase muchos en algunos rebatos» (1690: 460). 
Ese espacio en el que se encuentra el oratorio es móvil, pues una acotación posterior indica:

Vuélvase todo el teatro con todos tres, y quede a las espaldas del oratorio una muerte espantosa amenazándole [al Principe] con su guadaña, y luego vuelva todo a cubrirse con el primer lienzo (272v.).

La segunda parte del auto, que nos traslada a la bahía de Cádiz, cuenta con un lienzo de fondo que representa la muralla de la ciudad, sobre la cual aparecen en varios momentos algunos personajes. Se utiliza el «bofetón» para la aparición de un ángel sobre el tablado, montado a caballo y armado, que desaparece por el mismo procedimiento: «Sale de un lado en un bofetón un ángel armado en un caballo y dé una vuelta hasta ponerse en medio del tablado» (277v.).

La confrontación bélica se inicia con el descubrimiento de una galera con algunos soldados ingleses, que simboliza a la Herejía, comandada por el Error (el Príncipe):

Tocan una trompeta y suenan fuegos, y descúbrese por un lado, en un lienzo de aguas, una galera llena de jarcias y gallardetes; dentro algunos soldados; en el estandarte pintada la Herejia, con un libro en las manos; y en los remos escritos algunos de estos nombres: Caloino, Lutero, Arriano, Maniqueo, Marción y Eunomio; y en lo alto el Principe armado todo con plumas y bastón. $Y$ vaya, al son de los fuegos y la trompeta, acercándose al muro (279v.-280r.)

En el momento culminante del auto, esta galera se enfrentará con la de la $\mathrm{Fe}$, como de nuevo se exige en una compleja acotación, en la que vale la pena detenernos por su detallismo, repleto de valor simbólico:

Suenan chirimias, y viene por el otro lado una galera muy bien aderezada. Trairá pintados en el estandarte los patrones de Sevilla; en lo alto las armas de la Ciudad y de la Iglesia; en los costados cabezas de ángeles. Los remos con estas letras: Augustinus, Hieronimus, Irineus, Ambrosius, Seotus y otros. Vendrá la galera llena de roscas y panes; en medio un cáliz grande y una hostia, a un lado la Iglesia, que hará una niña con capa de coro y un cetro (284v.)

La simbología, tan presente en el género sacramental (recordemos la cruz que porta la Infanta en representación de la Fe, mencionada más arriba), se materializa por medio de estas galeras cargadas de elementos que visualmente cifran alusiones a la confrontación entre la Fe católica y la Herejía. La galera de la Fe es la más rica en implicaciones alusivas a los símbolos del catolicismo, especialmente los sacramentales, y a la defensa que de la fe hicieron quienes enfrentaron diferentes herejías. Pero también en ella se pretende poner de relieve el papel protagonista que en la defensa histórica de Cádiz tuvieron la Ciudad de Sevilla, y su Iglesia, subrayada por sus armas y patronos (San Isidoro y Santas Justa y Rufina) pintados en el estandarte. En las relaciones de la época se destaca, en efecto, su presteza y 
liberalidad en el envío de víveres a las tropas, representados por las roscas y los panes que porta la galera. Algo que no resulta extraño en el contexto de la fiesta del Corpus sevillana, en el que, como antes señalé, se debió de estrenar el auto.

Si durante todo el desarrollo argumental de la pieza, el enfrentamiento religioso y el motivo de la eucaristía como identificador de la Fe están presentes, es en el momento de llegar a su culminación cuando se convierte en la piedra angular sobre la que cobra sentido plenamente la construcción dramática, subrayada por el efecto de la música, la tramoya y el fuego. El misterio eucarístico, la transformación a la vista del público del pan y el vino, se representa mediante la desaparición del cáliz y la hostia y la aparición de «un cristo resucitado muy hermoso» (285v.), a la vez que arde en llamas la galera de la Herejía. Efectivamente, los ingleses antes de marchar reunieron los cuerpos muertos de sus compatriotas en una galera a la que prendieron fuego.

El socorro de Cádiz, con un anclaje tan cercano a la realidad contemporánea, resulta un auto sorprendente que, como he tratado de destacar, utiliza en su planteamiento elementos que remiten al drama de hechos contemporáneos, pero que al mismo tiempo se erige en una pieza muy bien construida, que sirve, al igual que cualquier auto sacramental, al propósito de afianzamiento de la fe católica y de sus dogmas diferenciales. Es precisamente esa hibridez que tanto desagradaba a Menéndez Pelayo, su anclaje a circunstancias de la realidad, lo que convierten este auto hoy en una pieza que cobra un especial interés a nuestros ojos para comprender el contexto de una época de la historia de España en la que los intereses de la iglesia católica y los de la monarquía iban de la mano. 


\section{Bibliografía}

Anónimo, Copia de la carta que el señor don Fernando Girón, capitán general de la infantería de Cádiz, envió al señor excelentísimo Duque de Medina, y la orden que del Consejo se le envió al señor don Fadrique de Toledo, con el valeroso hecho que hizo el mancebo Platero, hijo de Sevilla, Sevilla, Juan de Cabrera, 1625. Biblioteca de la Universidad de Sevilla. Fondo antiguo, A 109/085 (178).

Alenda y Mira, Jenaro, «Catálogo de autos sacramentales, historiales y alegóricos», Boletín de la Real Academia Española, IX (1922), 488-499.

Concepción, Jerónimo de la, Emporio de el orbe, Cádiz ilustrada, investigación de sus antiguas grandeza... Amsterdan, Joan Bus, 1690 (libro VI, cap. XIV) Biblioteca de la Universidad de Sevilla. Fondo antiguo, A 025(b)/268.

Cruickshank, Don W., «LLisping and wearing strange suits»: personajes ingleses en la escena española y personajes españoles en la escena inglesa. 15801680», en Anita K. Stoll, Vidas paralelas: el teatro español y el teatro isabelino, Londres, Tamesis Books, 1993, pp. 7-23.

-, Calderón de la Barca, Madrid, Gredos, 2011, traducción de la primera ed. en inglés (2009).

Díaz-Plaja, Fernando, Historia de España en sus documentos. Siglo XVII, Madrid, Cátedra, 1987.

Elliott, John E., El conde-duque de Olivares: el político en una época de decadencia, Barcelona, Crítica, 1991 (ed. en castellano revisada; $1^{\text {a }}$ ed. en inglés 1986).

Ferrer Valls, Teresa (dir.), et al., Diccionario biográfica de actores del teatro clásico español. DICAT, Kassel, Edition Reichenberger, 2008.

Gamboa y Eraso, Luis, Verdad de los sucedido con ocasión de la venida de la armada inglesa del enemigo sobre Cádiz, Córdoba, Salvador de Cea, 1626, Biblioteca de la Universidad de Sevilla. Fondo antiguo, A 109/088 (11).

Garrot Zambrana, Juan Carlos, «Caraluña en dos autos sacramentales de Calderón», en Ignacio Arellano (ed.), Calderón 2000. Homenaje a Kurt Reichenberger en su 80 cumpleaños. Actas del Congreso Internacional, IV Centenario del nacimiento de Calderón, Kassel Edition Reichenberber, 2002, 775-790.

Greer, Margaret R., "Cazadores divinos, demoniacos y reales en los autos de Calderón de la Barca» en Ignacio Arellano, Juan M. Escudero, Blanca Oteiza y $\mathrm{M}^{\mathrm{a}}$ Carmen Pinillos (eds.), Actas del Congreso Internacional Divinas y humanas letras. Doctrina y poesía en los autos sacramentales de Calderón. Universidad de Navarra, 26 de febrero-1 de marzo, 1997, Kassel, Edition Reichenberger, 1997, 217-244.

Herrera, Rodrigo, Comedia famosa de La fe no ha menester armas, y venida del inglés a Cádiz, Valencia, Joseph de Orga, 1762, Biblioteca Menéndez Pelayo de Santander, sign. 31162.

Lohmann Villena, Guillermo, El arte dramático en Lima durante el virreinato, 
Madrid, Escuela de Estudios Hispanoamericanos de la Universidad de Sevilla, 1945.

Menéndez Pelayo, Marcelino, Estudios sobre el teatro de Lope de Vega, t. I, Santander, CSIC, 1949.

Pérez de Montalbán, Juan, El socorro de Cádiz, auto sacramental, Bilioteca Lárazo Galdiano de Madrid, Inventario 15585, signatura MC 6-10.

Profeti, Maria Grazia, Per una bibliografia de J. Pérez de Montalábán, Verona, 1976.

Puyuelo y Salinas, Carlos, Carlos de Inglaterra en España: un principe busca novia en Madrid, Madrid, Escelicer, 1962.

Redondo, Agustín, "Fiesta y literatura en Madrid durante la estancia del príncipe de Gales en 1623», Edad de Oro, XVII (1998), 119-36.

Rull, Enrique, Arte y sentido en el universo sacramental de Calderón, Pamplona, Kassel, Edition Reichenberger, 2004. 307

—, «El auto sacramental y la corte en la época de Felipe IV», en prensa.

SÁEZ, Adrián J., "Doctrina, historia y política en cuatro autos de Calderón con la guerra de Cataluña al fondo», Theatralia. Revista de poética del teatro, XIV (2012), 119-45

Sanz Camañes, Porfirio, Diplomacia hispano-inglesa en el siglo XVII: razón de estado y relaciones de poder durante la guerra de los Treinta años, 1618-1648, Cuenca, Ediciones de la Universidad de Castilla-La Mancha, 2002.

Soons, Alan, "El valle de la zarzuela de Calderón, un enigma espinoso», Criticón, 31 (1985), 45-57.

Urzáiz Tortajada, Héctor, Catálogo de autores teatrales del siglo XVII, 2 vols., Madrid, FUE, 2002, 2 volúmenes.

VAlladares Ramírez, Rafael, «El vellón bueno. Notas sobre un auto sacramental de 1660", Cuadernos de Historia moderna, 23 (1999), 129-40.

Yeves Andrés, Juan Antonio, Manuscritos españoles de la Biblioteca Lázaro Galdiano, Madrid, Ollero \& Ramos y Fundación Lázaro Galdiano, 1998, 2 volúmenes. 